\title{
KONSEP PEMBENTUKAN KARAKTER PRIBADI ANAK MENURUT PEMIKIRAN ALBERT BANDURA DAN MUHAMMAD MUTAWALLI AL-SYA'RAWI
}

\author{
Anida Magfirah \\ Alumni Fakultas Ushuluddin dan Humaniora \\ IAIN Antasari Banjarmasin
}

Diterima tanggal 21 Mei 2015 / Disetujui tanggal 25 Juni 2015

\begin{abstract}
The globalization brings many impacts in the world. In Indonesia, some people consider it as a threat for the local wisdom and national culture. In this era, the flow of information cannot be repressed, so all people can access it easily. Somehow it will be positive, but the reality said that the negative impacts is bigger for the community especially for the young generation. To prevent the things happen, it is needed for them to have strong character in their personality. This writing discussed about the concept of building the children's character since early. So far, the article is going to compare the thought of Albert Bandura and Mubammad Mutawwali al-Sya'rawi in building character. In the end, it will be concluded the differences and the similarities between both concepts.
\end{abstract}

Kata kunci: Karakter, Modelling, Keteladanan.

\section{Pendahuluan}

Fenomena globalisasi adalah dinamika yang paling strategis dan membawa pengaruh dalam tata nilai dari berbagai bangsa termasuk bangsa Indonesia. Sebagian kalangan menganggapnya sebagai ancaman yang berpotensi untuk menggulung tata nilai dan tradisi bangsa dan menggantinya dengan tata nilai yang popular di negara asing. Di era globalisasi yang tidak mampu menahan derasnya arus informasi dari dunia manapun, membuat generasi muda dengan mudah mengetahui dan menyerap informasi dan budaya dari negara lain, demikian sebaliknya negara manapun dapat dengan mudah mendapatkan segala bentuk informasi dan budaya dari negara. Arus globalisasi begitu cepat merasuk ke dalam masyarakat terutama di kalangan generasi muda. Pengaruh globalisasi terhadap generasi muda begitu kuat sehingga menjadikan banyak generasi muda kehilangan kepribadian diri sebagai bangsa Indonesia.

Fenomena negatif generasi muda seolah mempertanyakan kembali peranan pembentukan karakter dalam membangun etika dan moral masyarakat. ${ }^{1}$ Hal ini menunjukkan adanya kesenjangan antara apa yang terjadi pada kenyataan dengan norma-norma yang sudah ada, baik dari norma agama maupun norma negara Indonesia itu sendiri.

Dalam upaya membentengi generasi muda khususnya pelajar agar tidak terlindas oleh arus globalisasi maka diperlukan pembentukan karakter yang kuat. Membentuk karakter tidaklah segampang membalikkan telapak tangan, meskipun tidak mudah namun membentuk karakter sangat penting, apalagi bagi generasi muda yang merupakan komponen bangsa Indonesia yang paling rentan

\footnotetext{
${ }^{1}$ Neneng Siti Fatimah Nurul Aini, "Pendidikan Karakter Dalam Pemikiran Azyumardi Azra”,pdf (skripsi fakultas Tarbiyah dan Keguruan Universitas Negeri Sunan Kalijaga Yogyakarta, 2012), 1. (18 Januari 2015).
} 
dalam menghadapi terpaan arus globalisasi. Karena bagaimanapun juga generasi muda kita adalah cerminan karakter bangsa Indonesia. Apabila generasi muda kita tidak menjunjung tinggi nilai dan norma menurut falsafah Pancasila maka dapat dikatakan karakter bangsa kita memudar dan hilang, bila karakter suatu bangsa hilang maka tidak ada lagi nama bangsa Indonesia di peta dunia.

Berbicara tentang karakter, istilah nation and character building adalah istilah klasik dan menjadi kosa kata hampir sepanjang sejarah modern Indonesia terutama sejak peristiwa Sumpah Pemuda 1928. Istilah ini muncul kembali sejak tahun 2010 ketika pendidikan karakter dijadikan sebagai gerakan nasional pada puncak acara Hari Pendidikan Nasional 20 Mei 2010. Selain itu pula, berita terbaru yang terjadi di dunia pendidikan Indonesia adalah perpindahan Kurikulum Tingkat Satuan Pendidikan (KTSP) menjadi Kurikulum 2013. Penyusunan Kurikulum 2013 yang dilakukan oleh pemerintah merupakan sebuah proses yang biasa terjadi dalam dunia pendidikan dan pergantian kurikulum ini dilakukan karena adanya tuntutan perkembangan ilmu, pengetahuan, teknologi dan budaya masyarakat. Dalam berbagai kesempatan, Mendikbud di era Presiden Susilo Bambang Yudhoyono, Mohammad Nuh menyatakan bahwa pendidikan karakter dan budi pekerti mendapat perhatian khusus dalam Kurikulum 2013. ${ }^{2}$ Latar belakang munculnya pendidikan karakter ini karena semakin terkikisnya karakter sebagai bangsa Indonesia, dan sekaligus sebagai upaya pembangunan manusia Indonesia yang berakhlak budi pekerti yang mulia. ${ }^{3}$

Pada dasarnya segala perilaku haruslah diselaraskan dengan norma-norma moral agama, tradisi, hukum dan norma moral lainnya yang berlaku dalam masyarakat. ${ }^{4}$ Sejak dahulu, karakter sopan santun dan tata krama sangat dijunjung tinggi, apalagi dalam agama Islam. Hal ini ditunjukkan dengan adanya perkataan seorang sufi yang bernama Ibnu Mubârak yang sangat mengedepankan sopan santun di atas segalanya. Beliau mengatakan bahwa untuk masalah budi pekerti, meskipun sedikit itu lebih penting diperlukan daripada hanya banyak ilmu. ${ }^{5}$

Seorang tokoh Islam yang sangat terkenal seperti Imam Ghazali pun sangat mementingkan dengan kesopanan dan budi pekerti. Beliau menyatakan bahwa budi pekerti itu ialah pancaran naluri jiwa manusia yang dapat melahirkan suatu tindakan dan kelakuan dengan senang dan mudah tanpa rekaan pikiran. Jika naluri tersebut melahirkan suatu tindakan dan kelakuan yang baik lagi terpuji menurut akal dan syari'at maka ia dinamakan budi pekerti yang baik. Namun sebaliknya, ketika naluri itu melahirkan sesuatu perbuatan yang jahat maka ini dinamakan dengan budi pekerti yang buruk. ${ }^{6}$ Maka dari itu Islam adalah agama yang sangat menjunjung tinggi pada pembentukan akhlak dan budi pekerti bagi setiap manusia.

Setiap waktunya manusia berhak dalam perkembangan akhlak dan karakternya namun golden age adalah waktu yang ideal dalam pembentukan akhlak dan karakter bagi setiap manusia. Maka dari itu, keterlibatan orangtua sangat penting dalam upaya pembentukan karakter anak sejak dini. Salah satu hal yang terpenting diajarkan kepada anak dalam prinsip pembentukan karakter anak adalah

${ }^{2}$ Ki Supriyoko, “Membangun Karakter Peserta Didik Melalui Kurikulum 2013”, 2013, http:/ / dinamikaedukasidasar.org/ membangun-karakter-peserta-didik-melalui-kurikulum-2013/ (26 Februari 2015).

${ }^{3}$ Tobroni, "Pendidkan Karakter Dalam Perspektif Islam", 2010, http:/ / tobroni.staff.umm.ac.id/2010/11/24 (5 Desember 2014).

${ }^{4}$ Tohirin, Psikologi Pembelajaran Pendidikan Agama Islam (Jakarta: Raja Grafindo Persada, 2005), 43.

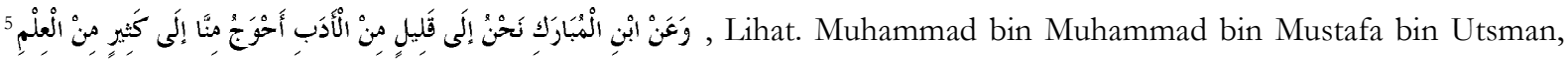
Bariiqah Mahmudiyyah, jilid. 3 (tt: Matba'ah Al-Halaby, 1348H), 145.

"Adi Budi Kristianto, "Konsep Akhlak Menurut Al-Ghâzali", 2014, bttp://www.academia.edu/4861329/ Konsep_Etika_menurut_Al-Ghazali (24 januari 2015). 
dilihat dari perilaku yang dicontohkan oleh orangtua itu sendiri. Membentuk karakter anak yang berkualitas tidak lain juga berarti proses penanaman akhlak mulia pada diri anak tersebut.

Manifestasi kerasulan Nabi Muhammad ini mengindikasikan bahwa pembentukan karakter merupakan kebutuhan utama bagi tumbuhnya cara beragama yang dapat menciptakan peradaban. ${ }^{7}$ Sehingga penulis tertarik untuk menggali lebih dalam permasalahan tersebut dari berbagai sumber, yang salah satu diantaranya adalah pemikiran-pemikiran tentang pembaharuan proses yang dialami pada anak, khususnya pembentukan karakter.

Setelah kemudian penulis berusaha memilah pemikiran dan gagasan dari berbagai pakar ahli, pilihan penulis jatuh kepada seorang tokoh yang memiliki pemikiran dan gagasan yang begitu cemerlang. Beliau adalah Albert Bandura, seorang ahli Psikologi yang sangat terkenal dengan teori pembelajaran sosial. Beliau lahir di Mundare Northern Alberta Kanada, pada 04 Desember 1925. Masa kecil dan remajanya dihabiskan di desa kecil dan juga mendapat pendidikan. Pada tahun 1949 beliau mendapat pendidikan di University of British Columbia, dalam jurusan Psikologi. ${ }^{8}$ Beliau terkenal dengan teori modelling dalam ilmu Psikologi. Salah satu konsep dalam aliran behaviorisme. Modelling adalah proses belajar dengan mengamati tingkah laku atau perilaku dari orang lain di sekitarnya. Menurut Bandura, sebagian besar tingkah laku manusia dipelajari melalui peniruan maupun penyajian, hasil eksperimennya mendapati, bahwa peniruan dapat berlaku hanya melalui pengamatan terhadap perilaku model (orang yang ditiru) meskipun pengamatan itu tidak dilakukan terus menerus. Proses belajar semacam ini disebut observational learning atau pembelajaran melalui pengamatan. Maka dari itu modelling ini dapat menjadi bagian yang sangat penting dan powerfull pada proses pembelajaran. Jadi, inti dari pembelajaran dengan mengamati adalah permodelan (modelling).

Tokoh lain yang juga menjadi pilihan penulis adalah seorang mufassir sekaligus cendekiawan muslim bernama Muhammad Mutawalli al-Sya'râwi yang lahir di Republik Arab Mesir pada tanggal 16 April tahun 1911 M dengan pemikiran-pemikiran briliant yang termaktub dalam kitab tafsir mengenai pembaharuan pembentukan karakter. Beliau adalah salah satu ahli tafsir Alquran yang terkenal pada masa modern dan merupakan Imam masa kini. Beliau menekankan pada suri teladan yang baik untuk keberlangsungan proses pembentukan karakter pada anak. Pemikiran al-Sya'rawi tentang suri teladan yang menjadi titik pembentukan karakter anak ini tertuang pada tafsir Alquran di dalam surah al-Ahzab ayat $21 .^{10}$

Kedua tokoh tersebut menfokuskan perhatian pada pembentukan karakter anak, meskipun berbeda pendekatan. Keduanya menganggap penting persoalan pembentukan karakter khususnya karakter anak. Untuk mengkaji lebih dalam pandangan mereka perlu penelitian khusus yang bersifat komparatif analitis.

\section{Sekilas tentang Albert Bandura dan Muhammad Mutawalli asy-Sya'rawi}

Albert Bandura lahir tanggal 4 Desember 1925, di kota kecil Mundare bagian selatan Alberta, Kanada. Seperti Skinner, dia hidup di sebuah kota yang sangat kecil. ${ }^{11}$ Ia tumbuh sebagai anak laki-

${ }^{7}$ BambangQ-Anees dan Adang Hambali, Pendidikan Karakter Berbasis Al-Qur'an (Bandung: Simbiosa Rekatama Media, 2008), 100.

${ }^{8}$ C. George Boeree, Personality Theories, cet. IV (Yogyakarta: Prismasophie, 2010), 238-239.

${ }^{9}$ Jess Feist, Gregory J. Feist, Theories of Personality (Yogyakarta: Pustaka Pelajar, 2008), 409.

${ }^{10}$ Midi Muhammad Idit, “Biografi Syaikh M. Mutawalli asy-Sya'rawi”, 2014, bttp:// www.muslimedianews.com/2014/01/ biografi-syaikh-m-mutawalli-asy-Syarawi.html (24 Januari 2015). 
laki satu-satunya dari keluarga dengan lima kakak perempuan. Ayahnya berasal dari Polandia dan ibunya berasal dari Ukraina. Kedua orangtuanya telah berimigrasi dari negara Eropa Timur saat mereka remaja. Bandura didukung oleh kakak-kakak perempuannya untuk menjadi mandiri dan dapat bergantung pada dirinya sendiri. Ia juga belajar untuk mengarahkan dirinya sendiri di sekolah kecil yang ada di kotanya. ${ }^{12}$ Kebanyakan dari publikasi Albert Bandura adalah di dalam ranah Psikologi klinis, terutama yang bergelut dengan psikoterapi dan tes Rorschach. ${ }^{13}$

Pada tahun 1953, Bandura bergabung dengan Fakultas Psikologi di Stanford dan berkarya di sana hingga ia pensiun. ${ }^{14}$ Pada tahun yang sama ia bekerja bersama salah seorang anak didiknya, Richard Walters. Buku pertama hasil kerja sama mereka berjudul Adolescent Agression terbit tahun 1959. ${ }^{15}$ Sejak saat itu, Bandura terus menerbitkan beragam buku dengan subjek yang bervariasi, seringkali berkolaborasi dengan mahasiswa pascasarjana. Buku-bukunya yang paling berpengaruh adalah Social Learning Theory (1977), Social Foundation of Thought and Action (1986), dan Self-Efficacy the Exercise of Control (1997). Psikolog Amerika ini adalah pencipta utama teori sosial kognitif kontemporer. Fokus penelitiannya ada pada pembelajaran pengamatan, yaitu pembelajaran yang terjadi melalui pengamatan terhadap apa yang dilakukan orang lain. Pembelajaran pengamatan juga disebut sebagai imitasi atau modelling.

Adapun Muhammad Mutawalli al-Sya'rawi atau yang lebih akrab disapa dengan Sya'rawi lahir di Mesir tepatnya di Desa Daqadus, sebuah desa kecil yang terletak Kepulauan Timur Kecamatan Mait Gamair Kepulauan Dakhaliyah, pada hari Ahad tanggal 17 Rabi' al-Tsani 1329 H/ 16 April 1911 M. Di usia 87 tahun, pada hari Rabu 17 juni 1998 M, Muhammad Mutawalli al-Sya'rawi wafat. Jasadnya dimakamkan di Mesir. ${ }^{16}$

Karirnya diawali sebagai tenaga pengajar di ma'had al-Azhar Thantha, ma'bad Alexandria, ma'bad Zaqaziq, kemudian mengajar di ma'had Thantha lagi. Beliau juga menjadi dosen Jurusan Tafsir Hadis di Fakultas Syari’ah Universitas Mâlik 'Abdul 'Aziz di Makkah selama sembilan tahun. Ia juga diangkat menjadi wakil kepala sekolah di Al-Azhar, pernah memangku jabatan sebagai direktur dalam pengembangan dakwah Islam pada departemen wakaf tahun 1961 M. Beliau mulai terkenal ketika menjadi seorang da'i pada tahun 1973. Sya'rawi ditawari mengisi acara Nûr 'ala an-Nûr di stasiun televisi Mesir, mulailah namanya mencuat dan terkenal sebagai dâ’i yang kondang. Begitu banyak karir beliau dalam bidang pembelajaran, dalam bidang pemerintahan maupun bidang dầi, sehingga tidak bisa disebutkan satu persatu.

\section{Pemikiran Tokoh Tentang Pembentukan Karakter Pribadi Anak}

\section{Pemikiran Albert Bandura}

Salah satu kontribusi besar Albert Bandura dalam proses pembentukan karakter manusia adalah Pembelajaran Observasional atau bisa dinamakan dengan imitasi atau modelling. Pembelajaran Observasional adalah pembelajaran yang dilakukan ketika seseorang mengamati dan meniru perilaku

${ }^{11}$ William Crain, Teori Perkembangan Konsep dan Aplikasi, terj. Yudi Santoso, edisi ke-3 (Yogyakarta: Pustaka Pelajar, 2007), 302.

${ }^{12}$ Jess Feist dan Gregory. J. Feist, Theories of Personality, Teori Kepribadian, terj. Smita Prathita Sjahputri (Jakarta: Salemba Humanika, 2010), 201.

${ }^{13}$ Jess Feist dan Gregory. J. Feist, Theories of Personality, 202

${ }^{14}$ William Crain, Teori Perkembangan Konsep dan Aplikasi, 302.

${ }^{15}$ George C. Boeree, Personality Theories, 239. 
orang lain. Kapasitas untuk mempelajari pola perilaku dengan observasi dapat mengeleminasi pembelajarn trial and error. Dalam banyak kasus, pembelajaran observasional membutuhkan lebih sedikit waktu dalam hal pembelajarannya. ${ }^{17}$

Bandura yakin bahwa pembelajaran melalui modelling lebih efisien daripada belajar melalui pengalaman langsung. Dengan mengobservasi orang lain, manusia tidak perlu mengalami berbagai respon yang berakibat pada hukuman atau tanpa menghasilkan penguatan sama sekali. Sebagai contoh, anak mengobservasi karakter orang terdekatnya dalam hal ini adalah orangtua, dan mengulang apa yang dilihat dan didengarnya. Hal inilah yang disebut modelling. ${ }^{18}$

Inti dari pembelajaran observasional adalah modelling. Pembelajaran melalui modelling meliputi menambahi atau mengurangi suatu perilaku yang diobservasi dan menggeneralisasikan dari satu observasi ke observasi lainnya. Dengan perkataan lain, modelling meliputi proses kognitif dan bukan sekedar imitasi. Modelling lebih dari sekedar mencocokkan perilaku dari orang lain, melainkan mempresentasikan secara simbolis suatu informasi dan menyimpannya untuk digunakan di masa depan. ${ }^{19}$

Ada beberapa faktor yang menentukan seseorang akan belajar dari seorang model dalam situasi tertentu, yaitu:

a) Karakteristik model.

b) Karakteristik dari yang melakukan observasi.

c) Konsekuensi dari perilaku yang akan ditiru.

Selanjutnya Bandura memaparkan tahapan-tahapan yang harus dilakukan, yaitu sebagai berikut:

a) Tahap perhatian atau atensi (attention).

b) Tahap penyimpanan dalam ingatan atau retensi (retention).

c) Tahap reproduksi.

d) Tahap motivasi. ${ }^{20}$

\section{Pemikiran Muhammad Mutawalli al-Sya'rawi}

Dalam Alquran terdapat surat al-Ahzâb ayat 21 yang membicarakan tentang keteladanan Rasulullah. Ayat ini banyak ditafsirkan oleh para mufassîr dan dijadikan sebuah pedoman dalam usaha memperbaiki perilaku manusia. Perilaku seorang Muslim yang baik idealnya haruslah bersumber dari ajaran-ajaran agama Islam yang dibawa oleh Nabi Muhammad. Muhammad Saw. adalah sumber yang menjadi mata air yang mengaliri seluruh kebaikan manusia. Tentu saja banyak orang lain yang dapat dijadikan panutan, pembimbing dan pemimpin. Namun kebaikan dan kebenaran hanyalah fatamorgana jika ia tidak menghulu pada "sang sumber" kebenaran insani, yakni Muhammad Saw.

Di dalam kitabnya al-Sya'rawi memaparkan bahwa Allah swt memuji kepada Nabi Muhammad Saw. Beliau memaparkan bahwa teladan insani yang terbaik, tertinggi dan termulia ialah Muhammad bin Abdullah, Rasulullah Saw. ${ }^{21}$ Hal ini sesuai dengan firman Allah Swt. dalam surah al-Ahzâb ayat 21:

\footnotetext{
${ }^{16}$ Herry Muhammad, Tokoh-Tokoh Islam yang Berpengarub Abad 20 (Jakarta: Gema Insani Press, 2006), 277.

${ }^{17}$ John W. Santrock, Psikologi Pendidikan, terj. Tri Wibowo B. S, (Jakarta: Prenada Media Group, 2010), 286.

${ }^{18}$ Albert Bandura, Social Learning Theory, 11

${ }^{19}$ Albert Bandura, Social Learning Theory, 11.

${ }^{20}$ Albert Bandura, Social Learning Theory, 217-218.

${ }^{21}$ Muhammad Mutawalli al-Sya'rawi, Tafsir al-Sya'rawi, jilid.19 (Al-Qahirah: Akhbar Al-Yaum, 1999), 11979.
} 


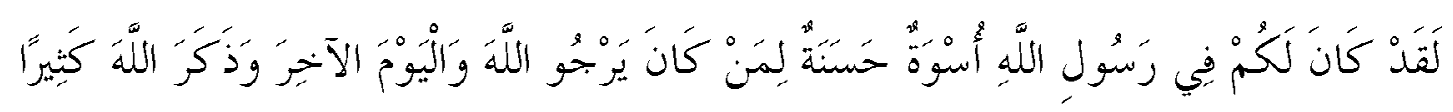

Allah Swt. memuji Nabi Muhammad Saw. sebagai pribadi yang berakhlak agung yang dalam dirinya terdapat suri teladan sehingga patut diikuti. Rasulullah Saw. sejatinya adalah seorang insan yang memiliki kepedulian dan kasih sayang yang tidak terbayangkan pada orang-orang yang beriman. Rasulullah Saw. adalah pribadi yang sangat agung dengan kapasitas (maknawi) yang tidak terbatas yang memiliki akhlak dan perilaku sangat istimewa. ${ }^{22}$

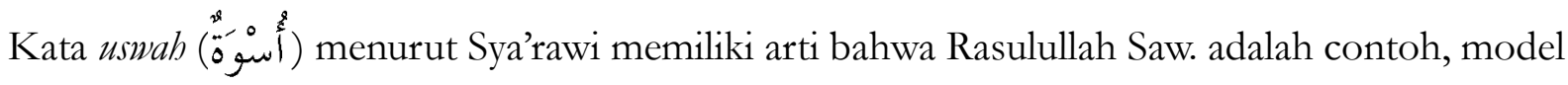
dan seorang behavioris di dalam segala aspek kehidupan. Rasulullah Saw. sebagai seorang muballigh atau seorang yang menyampaikan ayat-ayat Allah untuk selalu menjaga lisan dan perilaku manusia di dalam segala aspek kehidupan. Sehingga, menurut Sya'rawi pantaslah Rasulullah Saw. disebut sebagai uswah suluk $k^{23}$ (behavioris). Hal ini dikuatkan dengan perkataan istri Rasulullah Saw. yaitu Aisyah Ra. Beliau berkata:

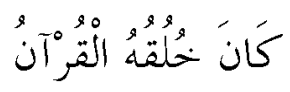

Atas dasar inilah, maka Islam menyeru agar orang Islam berhias diri dengan akhlak yang baik serta ditumbuhkembangkan di dalam jiwanya. Sebab, iman seseorang tergantung pada keutamaan jiwanya sebagaimana kualitas Islamnya pun tergantung pada kebaikan akhlaknya. Allah memuji Nabi Muhammad saw karena memiliki akhlak tinggi. Allah berfirman di dalam Alquran surat al-Qalam ayat 4:

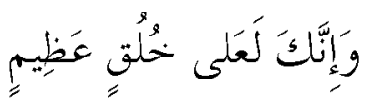

Allah juga berfirman di dalam Alquran surat Alî 'Imrân ayat 133-134:

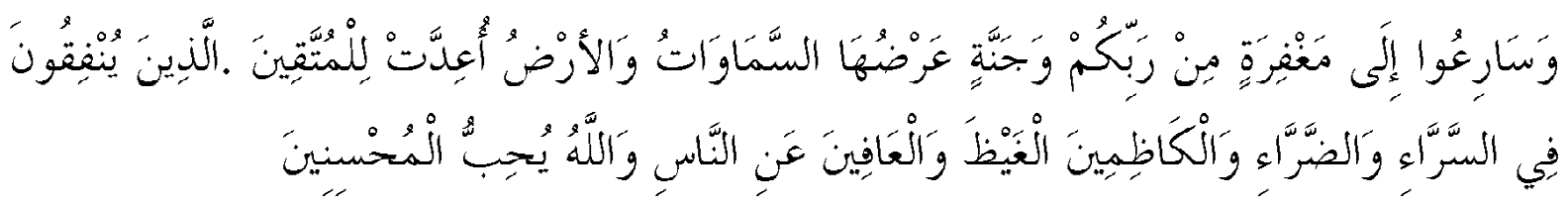

Berdasarkan ayat tersebut dijelaskan bahwasanya terdapat suri teladan yang baik, yaitu dalam diri Rasulullah Saw. yang dibekali akhlak yang mulia. ${ }^{24} \mathrm{Hal}$ ini memberikan pengertian tentang pentingnya pembentukan akhlak dalam kehidupan manusia. ${ }^{25}$ Sehingga dengan akhlak manusia dapat lebih mengutamakan kebaikan, kebenaran, senang kepada kebaikan, kemudian dibentuk dan dilatih untuk mencintai yang terpuji dan membenci yang tercela, maka sifat-sifat tersebut dapat menjadi karakter bagi jiwa, sehingga perbuatan-perbuatan positif dan sikap-sikap terpuji ini adalah apa yang dikenal dengan akhlak yang baik. ${ }^{26}$

Akhlak adalah tata cara berperilaku sesuai dengan norma dan aturan baik yang bersumber dari adat, negara dan agama. Akhlak agama adalah perilaku dengan nilai-nilai dan aturan agama, yang

${ }^{22}$ Rudi Mulyono, "Kalau Bukan Pada Muhammad, Kepada Siapa Lagi”, Bayan (Jurnal Kajïan Ilmu-Imu Islam), Vol. 11, No. (Tahun 2012), 103.

${ }^{23}$ Al-Sya'rawi, Tafsir al-Sya'rawi, 11979.

${ }^{24}$ Abu Bakr Jabir al-Jaza’iri, Pedoman Hidup Muslim, terj. Hasanuddin dan Didin Hafidhuddin (Jakarta: PT Pustaka Litera Antar Nusa, 2008), 226.

${ }^{25}$ Zainudin, "Pendidikan Anak Sebagai Tuntutan Masa Depan Anak", Ta'allum Jurnal Pendidikan Islam, 209.

${ }^{26}$ Al-Jaza'iri, Pedoman Hidup Muslim, 225. 
dianggap baik adalah menurut agama dan yang buruk adalah apa yang dianggap buruk oleh agama. Keluarga adalah sumber nilai dan norma agama yang pertama kali ditemukan oleh anak. Keluarga berkewajiban mengajarkan akhlak kepada anak, seperti kebenaran, kejujuran, keikhlasan, kesabaran, kasih sayang, pemurah, pemaaf, penolong, bersahaja dan sebagainya.

Cara yang dapat ditempuh orangtua dalam pembentukan karakter pribadi anak adalah dengan memberi contoh yang baik kepada anak dengan berpegang teguh kepada akhlak yang mulia. Maka dari itu, dalam hal pembentukan karakter pribadi anak (agama, sosial, dan lain-lain) hal yang pertama dilakukan oleh orangtua adalah dengan memberi teladan yang baik kepada anak. ${ }^{27}$ Agar keluarga dapat menjalankan fungsinya, maka orangtua harus menunjukkan melalui contoh yang baik, budi bahasa dan menetapkan akidah Islam. Ada landasan moral dan nilai yang dapat dijadikan oleh keluarga Muslim sebagai landasan mendorong dalam proses pembentukan karakter pribadi anak. ${ }^{28}$

Menurut Sya'rawi konsep teladan dalam pembentukan karakter pribadi anak dengan landasan akhlak mulia Rasulullah Saw. adalah konsep yang diajarkan Rasulullah bagi orang-orang yang selalu mengingat Allah dalam hidupnya. Mengenai pembentukan karakter pribadi anak, Sya'rawi berkata, "Yang terpenting dalam membentuk pribadi anak adalah suri teladan. Seandainya didapatkan suri teladan yang baik, seorang anak akan menjadikannya sebagai contoh. Maka seorang anak harus dicermati dengan baik, dan di sana terdapat perbedaan antara mengajari anak dan membentuknya." 29

Menurut Sya'rawi, seorang anak, jika tidak bergerak kemampuannya dan bersiap untuk menerima dan menampung sesuatu di sekitarnya, maka orangtua memiliki tugas besar dalam pengasuhannya. Hal ini berarti, apabila tidak siap telinganya untuk mendengar, kedua matanya untuk melihat, hidungnya untuk mencium, dan ujung-ujung jarinya untuk menyentuh, kita wajib menjaga seluruh kemampuannya dengan tingkah laku orangtua yang membentuk bersamanya dan di depannya. Oleh karena itu, orangtua harus menjaga telinganya dari setiap perkataan yang jelek, dan menjaga matanya dari setiap pemandangan yang merusak. Sya'rawi menambahkan bahwa orangtua harus membentuk karakter anak-anak dengan konsep yang Islami. Apabila anak melihat orangtua mengerjakan yang demikian itu, anak akan mengikutinya, begitu pula yang lainnya. Tapi jika anak itu tidak mengambil pelajaran dalam hal ini, tindakan lebih penting daripada omongan belaka. ${ }^{30}$ Sehingga teladan merupakan metode terbaik dalam pendidikan akhlak, karena sifat manusia adalah menirukan apa yang mereka lihat dan mereka dengar, terlebih pada masa anak-anak. ${ }^{31}$

Dalam fase dini pada kehidupannya, anak banyak belajar tentang berbagai kebiasaan dan tingkah laku melalui peniruan atau peneladanan terhadap kebiasaan dan tingkah laku kedua orangtuanya. Pada dasarnya hal ini karena bertolak pada tabiat manusia yang cenderung untuk meniru dan belajar banyak dari tingkah laku melalui peniruan, maka dari itu teladan yang baik sangat penting dalam pembentukan karakter anak. Nabi Muhammad Saw. sendiri menjadi teladan bagi para sahabat, istri, serta anak cucu beliau. ${ }^{32}$ Dari beliau mereka belajar bagaimana mereka melaksanakan berbagai ibadah. Selain aturan-aturan ibadah, para sahabat juga belajar dari beliau tentang tingkah laku yang baik,

\footnotetext{
${ }^{27}$ Moh. Padil dan triyo Suprayitno, Sosiologi Pendidikan, Keluarga, Masyarakat dan Sekolah (Malang: UIN-Maliki Press: 2010), 144.

${ }^{28}$ Al-Sya'rawi, Tafsir al-Sya'rawi, 11979.

${ }^{29}$ Al-Sya'rawi, Tafsir al-Sya'rawi, 11980.

${ }^{30} \mathrm{Al}-\mathrm{Sya}$ 'rawi, Tafsir al-Sya'rawi, 11980.

${ }^{31}$ Jamaal 'Abdur Rahman, Tahapan Mendidik. Anak Teladan Rasulullah, terj. Bahrun Abubakar Ihsan Zubaidi (Bandung: Irsyad Baitus Salam, 2005), 17.

32‘Abdur Rahman, Tahapan Mendidik. Anak Teladan Rasulullah, 175.
} 
akhlak yang luhur dan tata krama pergaulan. ${ }^{33}$ Melalui teladan yang baik, manusia belajar kebiasaan yang baik dan akhlak yang mulia. Sebaliknya, melalui teladan yang buruk, manusia pun akan belajar kebiasaan buruk dan akhlak yang tercela.

\section{Kajian tentang konsep pembentukan karakter pribadi anak}

Kajian tentang konsep pembentukan karakter pribadi anak disebut sebagai kajian yang sangat penting. Hal ini tidak saja posisinya sebagai problema awal kajian ini, tetapi lebih dari itu yaitu sebagai kajian yang menyentuh substansi dalam konsep yang disampaikan oleh kedua tokoh yaitu Bandura dan Sya'rawi.

Secara sederhana, Bandura memiliki konsep dalam pembentukan karakter anak dengan konsep pembelajaran observasional atau modelling, sementara Sya'rawi memiliki konsep dalam pembentukan karakter anak dengan konsep teladan. Pemikiran kedua tokoh tersebut memiliki kesamaan definisi namun dengan dasar, sumber, pendekatan, serta banyak hal yang berbeda di dalam mengkonsepkan pemikirannya.

Secara sederhana komparasi antara pemikiran kedua tokoh dapat diklasifikasikan sebagai berikut:

\begin{tabular}{|c|c|c|c|}
\hline No. & Bahan Komparasi & Bandura & Sya'rawi \\
\hline 1. & Konsep pemikiran & $\begin{array}{l}\text { Konsep modelling } \\
\text { pembelajaran yang terjadi } \\
\text { melalui pengamatan terhadap } \\
\text { apa yang dilakukan orang lain }\end{array}$ & $\begin{array}{l}\text { Konsep teladan } \\
\text { contoh yang baik kepada } \\
\text { anak dengan berpegang } \\
\text { teguh kepada akhlak yang } \\
\text { mulia }\end{array}$ \\
\hline 2. & Sumber pemikiran & $\begin{array}{l}\text { Himpiris } \\
\text { Konsep ini muncul dari hasil } \\
\text { eksperimen dan pengamatan } \\
\text { yang dilakukan oleh Albert } \\
\text { Bandura }\end{array}$ & $\begin{array}{l}\text { Normatif } \\
\text { Sya'rawi menemukan konsep } \\
\text { ini melalui penelaahan secara } \\
\text { mendalam pada Alquran dan } \\
\text { asbâb an-nurill Alquran }\end{array}$ \\
\hline 3. & $\begin{array}{l}\text { 'lokoh atau model } \\
\text { di dalam konsep } \\
\text { pemikiran }\end{array}$ & $\begin{array}{l}\text { Manusia yang memiliki } \\
\text { beberapa karakteristik model } \\
\text { ideal telah dijelaskan Albert } \\
\text { Bandura }\end{array}$ & $\begin{array}{l}\text { Rasulullah yang memiliki } \\
\text { kesempurnaan akhlak dan } \\
\text { kemuliaan yang diajarkan } \\
\text { melalui orangtua kepada anak }\end{array}$ \\
\hline 4. & 'lahapan & Ada (secara spesifik) & 'lidak ada \\
\hline 5. & Orientasi & Tidak ada & $\begin{array}{l}\text { Ada } \\
\text { Tertuju pada pembentukan } \\
\text { akhlak yang mulia, schingga } \\
\text { dengan momiliki akhlak yang } \\
\text { mulia dapat mencapai pahala } \\
\text { dan ridho } \Lambda \text { llah Swt. }\end{array}$ \\
\hline 6. & Pendekatan & Induktif & Deduktif \\
\hline
\end{tabular}

${ }^{33}$ Al-Sya'rawi, Tafsir al-Sya'rawi, 11981. 
Pada dasarnya pemikiran kedua tokoh ini memiliki kesamaan. Jika ditelaah lebih dalam, maka hasil yang didapatkan adalah bahwa Sya'rawi dengan konsep teladannya yang bertolak pada segala macam yang dikerjakan oleh orang yang memiliki perhatian yang besar dalam ajaran agama, terpilih dan terjamin memiliki akhlak dan patut untuk menjadi teladan, yaitu Rasulullah Saw. Hal ini sama detailnya dengan konsep yang diusung oleh Bandura dalam konsep modellingnya yang lebih mengedepankan dengan karakteristik model yang akan ditiru oleh anak dan tahapan-tahapan dalam proses modelling.

Sehingga dapat ditarik kesimpulan bahwa kedua tokoh memiliki kesamaan dalam teori yang dikemukakan oleh masing-masing tokoh tersebut. Namun, ada perbedaan dalam aspek karakteristik, sumber dan cara berfikir pada pemikiran kedua tokoh tersebut. Maka dari itu, konsep modelling dan konsep teladan adalah salah satu konsep yang tepat dalam upaya pembentukan karakter pribadi anak baik pada masa kedua tokoh tersebut maupun pada masa sekarang.

\section{Kesimpulan}

Konsep pembentukan karakter pribadi anak yang diangkat oleh Albert Bandura adalah konsep modelling yang memiliki fokus kajian pada Pembelajaran Observasional (modelling). Pembelajaran Observasional adalah pembelajaran yang dilakukan ketika seseorang mengamati dan meniru perilaku orang lain. Sedangkan konsep yang diangkat oleh Muhammad Mutawalli al-Sya'rawi adalah konsep teladan yang menitikberatkan pada mengikuti akhlak Rasulullah Saw.

Konsep kedua tokoh memiliki persamaan dan perbedaan yang cukup signifikan. Hal ini ditunjukkan pada sumber pemikiran, tokoh yang dijadikan model, tahap-tahapan dalam pembentukan karakter pribadi anak serta orientasi dalam konsep yang diangkat oleh masing-masing tokoh. Pembentukan karakter pribadi anak dalam pemikiran Albert Bandura dan Muhammad Mutawalli alSya'rawi adalah proses suatu bangsa dalam mempersiapkan generasi mudanya (pembentukan individu) untuk menjalankan kehidupan (sebagai khalifah) dan untuk memenuhi tujuan hidup secara efektif dan efisien berdasarkan sumber-sumber keilmuan Psikologi yakni, eksperimen dan observasi serta sumbersumber Islam yakni, Alquran dan Sunnah, sehingga akan terwujud Insân Kâmil. Dengan menerapkan nilai-nilai sosial seperti toleransi, demokratis, bersahabat dan komunikatif sebagai acuan dalam bertingkah laku dalam berinteraksi dengan sesama, nilai berkewarganegaraan, dan yang terakhir nilai religius. Pembentukan karakter pribadi anak karakter harus melibatkan semua komponen, keluarga, sekolah, masyarakat. Namun untuk pembentukan karakter pribadi anak yang paling terdekat dan sedini mungkin adalah dari orangtua.

\section{DAFTAR PUSTAKA}

Al-Abrasyi, Muhammad 'Athiyah. Dasar-Dasar Pokok Pendidikan Islam. terj. Bustami A. Gani dan Djohar Bahry L.I.S. Jakarta: Bulan Bintang. 1974.

Al-Abrasyi, Muhammad 'Athiyyah. Prinsip-Prinsip Dasar Pendidikan. Bandung: Pustaka Setia. 2003.

Aini, Neneng Siti Fatimah Nurul. "Pendidikan Karakter Dalam Pemikiran Azyumardi Azra”.pdf. Skripsi Fakultas Tarbiyah dan Keguruan Universitas Negeri Sunan Kalijaga Yogyakarta. 2012. (18 Januari 2015).

BambangQ-Anees dan Adang Hambali. Pendidikan Karakter Berbasis Al-Qur'an. Bandung: Simbiosa Rekatama Media. 2008. 
Bandura, Albert. Social Learning Theory.

Boeree, C. George. Personality Theories. cet. IV. Yogyakarta: Prismasophie. 2010.

Crain, William. Teori Perkembangan Konsep dan Aplikasi. terj. Yudi Santoso, edisi ke-3. Yogyakarta: Pustaka Pelajar. 2007.

Departemen Pendidkan Nasional Indonesia. KBBI. Cet. III. Jakarta: Balai Pustaka. 2005.

Feist, Jess dan Gregory J. Feist. Theories of Personality. Yogyakarta: Pustaka Pelajar. 2008.

- Theories of Personality (Teori Kepribadian). terj. Smita Prathita Sjahputri. Jakarta: Salemba Humanika. 2010.

Al-Ghazali, Abi Hamid Muhammad bin Muhammad bin Muhammad. Ibya Ulumuddin. Juz. III. Beirut: Dar Ihya al-Kutub al-Ilmiyah. t.th.

Harjali. "Pendidikan Karakter". Cendekia Jurnal Pendidikan Islam. Vol. 10. No. 2 (Juli-Desember 2012).

Idit, Midi Muhammad. "Biografi Syaikh M. Mutawalli asy-Sya'rawi”. 2014. http:// wnw.muslimedianews.com/2014/01/biografi-syaikh-m-mutawalli-asy-Syarawi.btml (24 Januari 2015).

Al-Jaza’iri, Abu Bakr Jabir. Pedoman Hidup Muslim. terj. Hasanuddin dan Didin Hafidhuddin. Jakarta: PT Pustaka Litera Antar Nusa. 2008.

Ki Supriyoko. “Membangun Karakter Peserta Didik Melalui Kurikulum 2013”. 2013. bttp:// dinamikaedukasidasar.org/membangun-karakter-peserta-didik-melalui-kurikulum-2013/ (26 Februari 2015).

Kristianto, Adi Budi. “Konsep Akhlak Menurut Al-Ghâzali”. 2014. bttp:/ / wnw.academia.edu/4861329/ Konsep_Etika_menurut_Al-Ghazali (24 Januari 2015).

Al-Maskawaih, Abu Ali Akhmad. Tahzib al-Akblak: Menuju Ksemepurnaan Akblak. terj. Helmi Hidayat. Cet. V. Bandung: Mizan. 1999.

Muhammad bin Muhammad bin Mustafa bin Utsman. Barïqah Mahmudiyyah, jilid. 3. tt: Matba'ah AlHalaby. $1348 \mathrm{H}$.

Muhammad, Herry. Tokoh-Tokoh Islam yang Berpengaruh Abad 20. Jakarta: Gema Insani Press. 2006.

Mulyono, Rudi. "Kalau Bukan Pada Muhammad, Kepada Siapa Lagi”. Bayan (Jurnal Kajian Ilmu-Imu Islam). Vol. 11. Tahun 2012.

Padil, Moh. dan Triyo Suprayitno, Sosiologi Pendidikan, Keluarga, Masyarakat dan Sekolah. Malang: UINMaliki Press: 2010.

Rahman, Jamaal 'Abdur. Tahapan Mendidik Anak Teladan Rasulullah, terj. Bahrun Abubakar Ihsan Zubaidi.Bandung: Irsyad Baitus Salam. 2005.

Salim, Ahmad. "Peningkatan kompetensi Peserta Didik Madrasah Melalui Pendidikan Karakter Berbasis Pesantren". Cendekia Jurnal Jurnal Pendidikan Islam. Vol. 10. No. 2. Desember 2012. 
Santrock, John W. Psikologi Pendidikan. terj. Tri Wibowo B. S. Jakarta: Prenada Media Group. 2010. Asy-Sya'rawi, Muhammad Mutawalli. Tafsir asy-Sya'rawi. Jilid 19. Al-Qahirah: Akhbar Al-Yaum, 1999. Tobroni. "Pendidikan Karakter Dalam Perspektif Islam". 2010. bttp://tobroni.staff.umm.ac.id/2010/ 11/24 (5 Desember 2014).

Tohirin. Psikologi Pembelajaran Pendidikan Agama Islam. Jakarta: Raja Grafindo Persada. 2005.

Zainudin. "Pendidikan Anak Sebagai Tuntutan Masa Depan Anak". Ta'allum Jurnal pendidikan Islam. Vol. 01. No. 02 (November 2013). 